\title{
First isolation and molecular characterization of Suid herpesvirus type 1 from a domestic dog in Argentina
}

\author{
Maria Soledad Serena ${ }^{1,2}$, Germán Ernesto Metz ${ }^{1,2}$, Maria Ines Lozada ${ }^{2,3}$, Carolina Gabriela Aspitia ${ }^{1,3}$, \\ Edgardo Héctor Nicolino ${ }^{4}$, Claudio Luis Pidone ${ }^{4}$, Melisa Fossaroli ${ }^{5}$, Agustin Balsalobre ${ }^{2}$, Maria Alejandra Quiroga ${ }^{3}$ \\ and Maria Gabriela Echeverria ${ }^{1,2, *}$ \\ ${ }^{I}$ Department of Virology, Faculty of Veterinary Sciences, National University of La Plata, La Plata, Argentina \\ ${ }^{2}$ CONICET (Scientific Research Council), CCT La Plata, National University of La Plata, La Plata, Argentina \\ ${ }^{3}$ Department of Pathology, Faculty of Veterinary Sciences, National University of La Plata, La Plata, Argentina \\ ${ }^{4}$ Department of Infectious Diseases, Faculty of Veterinary Sciences, National University of Rosario, Casilda, \\ Argentina \\ ${ }^{5}$ Department of Pathology, Faculty of Veterinary Sciences, National University of Rosario, Casilda, Argentina
}

\begin{abstract}
Since Aujeszky`s disease (pseudorabies), which is caused by Suid herpesvirus type 1 (SuHV-1), was first notified in Argentina in 1978, many SuHV-1 strains have been isolated from swine. However, this disease can affect other vertebrates, such as dogs (secondary hosts), and lead to fatal neurological disease. The objective of the current work is to report the first isolation and molecular characterization of SuHV-1 from a dead domestic dog from Santa Fe Province (Argentina), which had had nervous signs compatible with pseudorabies. Samples of brain and trigeminal ganglia from this dog were obtained and fixed in formol for histopathology, and virology studies were conducted after cell disruption. Supernatants of both samples were inoculated onto RK13 cells and, after $72 \mathrm{~h}$, DNA was extracted with phenol-chloroform. Purified DNA was cut with a restriction enzyme and subjected to agarose gel and an aliquot was used to amplify the $\mathrm{gD}$ and $\mathrm{gC}$ genes by PCR. The $\mathrm{gC}$ sequence was compared with other public sequences. The strain isolated from the dog was similar to other Argentinean swine strains.
\end{abstract}

Keywords: Argentina, Domestic dog, Suid herpesvirus 1.

\section{Introduction}

Pseudorabies, also known as Aujeszky's disease, is caused by Suid herpesvirus type 1 (SuHV-1), a member of the Alphaherpesvirinae subfamily. In pigs, which are the natural hosts of pseudorabies, the symptoms include various degrees of respiratory distress, nervous and genital disorders, and mortality, according to the age of the pig and the virulence of the virus strain involved (Wittmann, 1986). In addition, infection of pregnant gilts or sows frequently results in resorption, abortion, or birth of mummified fetuses or stillborn neonates. In pigs surviving acute infection, SuHV-1 develops latency, primarily in neuronal tissues, but also in lymphoid tissues. The virus may be transmitted by nose-to-nose contact, coitus, artificial insemination, fomites, or transplacentally (Cramer et al., 2011). A wide range of mammals and other vertebrate species, such as carnivores, rodents and ungulates, are susceptible to SuHV-1 infection (Müller et al., 2011). In these secondary hosts, SuHV-1 infection leads to fatal neurological disease; animals succumb to massive neurological dysfunction within a few days of disease onset. In general, disease in secondary hosts is observed only sporadically (Steinrigl et al., 2012).
Pseudorabies is a notifiable disease that causes substantial economic losses to the swine industry and has a major economic impact due to trade implications and income losses for farmers. In Argentina, since SuHV-1 was first isolated in 1978 (Ambrogi et al., 1981), many outbreaks have occurred in different parts of the country (Davido, 1981; Sager et al., 1984; Echeverría et al., 1991, 1992). In 1996, the National Animal Health Service of Argentina (SENASA) established a control program based on serological detection of infected animals without vaccine usage, in which all seropositive animals are segregated and/or slaughtered. Although SuHV-1 seroprevalence in Argentina is relatively low (around 18\%), in 1998, SENASA established a program that involved voluntary vaccination of animals with an inactivated glycoprotein $\mathrm{E}(\mathrm{gE})$-deleted vaccine and an ELISA that differentiated infected from vaccinated animals. However, both the importation of the vaccine and the ELISA were discontinued in 2001 because of the economic crisis in Argentina. Later, in 2016, SENASA implemented compulsory vaccination with the same kind of vaccine to continue with the eradication program. 
The pig population in Argentina is of around 5,200,000 pigs and is concentrated mainly in three Provinces: Buenos Aires, Córdoba and Santa Fe. Some pigs are also distributed in other Provinces such as Entre Ríos, Chaco and Salta. About $80 \%$ of the farms have about 10 animals each (small producers or subsistence production), whereas the other $20 \%$ of farms have about 100 to 500 animals each. The highest percentage of positive animals is found in small farms.

Herrmann et al. (1984) proposed the systematization of SuHV-1 genomic types based on genomic BamHI DNA restriction fragment length polymorphisms (RFLPs). The classification obtained was modified by Christensen (1995), who determined three genomic types (genotypes): type I (including seven subtypes and reported mainly in the United Kingdom, Sweden and New Zealand); type II (including two subtypes and reported in Japan and Central Europe); and type III (including two subtypes and reported in Denmark).

In our laboratory, eight SuHV-1 strains were isolated from 1988 to 2013 (Echeverría et al., 1992, 2000; Serena et al., 2010). Subtyping of the Argentinean field isolates of SuHV-1 (Serena et al., 2010) has clearly shown that all strains are genotype I, the same as that occurred in Central Europe (Herrmann et al., 1984), Northern Ireland (Todd and Mc Ferran, 1985), the United States (Ben-Porat et al., 1984; Pirtle et al., 1984), and New Zealand (Tisdall et al., 1988). Although only one strain isolated in Argentina and previously classified as genotype II has been isolated from animals imported from Holland (Echeverría et al., 1994), no new isolates belonging to genotype II have been reported since 1981. Previous reports mention that genotype II is common in Holland (Gielkens et al., 1985).

In Brazil, genotype II is predominant in the pig population (Piatti et al., 2001; Schaefer et al., 2006). As regards the SuHV-1 genotypes present in South America, no further information has been reported.

The molecular characterization of strains uncovers genetic variations but not necessarily epidemiological relationships, even if the strains analyzed come from geographically distant regions (Müller et al., 2010). By using RFLP and sequence analysis, in a previous study, we were able to distinguish the genotypes of the Argentinean SuHV-1 strains (Serena et al., 2010). The Argentinean genotype I strains were grouped mainly with isolates from North America, Brazilian genotype I strains, and the NIA-3 vaccine strain, whereas the Argentinean genotype II strains were grouped with the reference type II Yamagata S-81 strain and the Brazilian genotype II strains. Partial sequence analysis of this $\mathrm{gC}$ region allowed a clear differentiation between Argentinean isolates of genotype I and those of genotype II. All Argentinean genotype I strains and the NIA-3 gE-deleted vaccine strain had identical amino acid sequence (232 amino acids). This could indicate the introduction of SuHV-1 in Argentina from a common source. Although the Argentinean strains are not gE-deleted, they probably resulted from a recombination event (Serena et al., 2011).

Although, in many European countries, SuHV-1 has been eliminated from domestic pigs, it is being continuously reported in wild boar populations and in related hunting dogs (Cay and Letellier, 2009; Steinrigl et al., 2012). There has been an unpublished report of pseudorabies infection in Argentine dogs associated with an outbreak of SuHV-1 in La Pampa Province in 1986 (Moras et al., 1986).

The objective of the current work is to report the first isolation and molecular characterization of SuHV-1 from a dead domestic dog from Santa Fe Province, Argentina, which had had nervous signs compatible with pseudorabies.

\section{Tissue sampling}

\section{Materials and Methods}

Postmortem examination of the head from the domestic dog from Santa Fe Province was performed at the Virology Laboratory of the School of Veterinary Sciences of La Plata, Buenos Aires, Argentina. The map of geographical distribution of SuHV-1 in Caseros Department (Santa Fe, Argentina) was created using QGis (version 2.18.3). Samples collected at necropsy included samples of the brain and trigeminal ganglia. Half tissues were immersed in $10 \%$ neutral buffered formalin, and half stored at $-20^{\circ} \mathrm{C}$ for virus isolation and DNA extraction.

\section{Virus isolation and RFLP analysis}

Frozen-stored samples were homogenized in minimal essential medium (MEM) with L-glutamine and centrifuged at $5000 \mathrm{rpm}$ for $10 \mathrm{~min}$. The supernatant was inoculated onto confluent monolayers of RK13 (rabbit kidney) cells grown on six-well culture plates. The growth medium consisted of MEM supplemented with $10 \%$ fetal bovine serum (FBS). The inocula were allowed to absorb for $1 \mathrm{~h}$ at $37^{\circ} \mathrm{C}$ in an atmosphere of $5 \% \mathrm{CO}_{2}$ in air. After incubation, the inocula were removed and MEM with $2 \%$ FBS was added. Cell cultures were incubated at $37^{\circ} \mathrm{C}$ in an atmosphere of $5 \%$ $\mathrm{CO}_{2}$ and assessed daily for the occurrence of herpesvirus cytopathic effect (CPE). After exhibiting typical herpesvirus $\mathrm{CPE}$, the supernatant was harvested, aliquoted and frozen $\left(-80^{\circ} \mathrm{C}\right)$.

For DNA extraction, the infected cells were harvested and pelleted by centrifugation. The pellet cell was washed, suspended in phosphate buffered saline (PBS) and DNA was extracted using a commercial kit Wizard Genomic DNA Purification Kit (Promega) according to the manufacturer's protocol. The quantity and quality of DNA was determined by measuring absorbance at an OD260/OD280 ratio in a spectrophotometer SmartSpec 3000 (Bio-Rad, USA). 
For RFLP analysis, approximately $1.5 \mu \mathrm{g}$ of DNA solution was digested overnight with 2UI of BamHI at $37{ }^{\circ} \mathrm{C}$, and then separated by electrophoresis in $0.7 \%$ $(\mathrm{w} / \mathrm{v})$ agarose gel $(140 \times 150 \times 5 \mathrm{~mm})$ in TAE buffer $(40$ $\mathrm{mM}$ Tris-acetate $\mathrm{pH} 7.8,5 \mathrm{mM}$ sodium acetate, and 1 $\mathrm{mM}$ EDTA) at $20 \mathrm{~V}$ for $16 \mathrm{~h}$ at room temperature, stained with ethidium bromide, visualized and photographed under a UV illuminator.

\section{Detection of rabies virus}

Viral RNA was extracted from a brain sample by using TRIzol® (Invitrogen, Carlsbad, CA, USA), following the manufacturer's instructions. Reverse transcription and PCR amplification were achieved as previously described by Cisterna et al. (2005) and performed at the Virology Laboratory of the School of Veterinary Sciences of La Plata.

\section{$P C R$ amplification and sequencing}

PCR was performed in a DNA Thermal Cycler (PerkinElmer Cetus, Norwalk, CT, USA). PCR reactions were carried out according to the manufacturer's protocols using PCRMaster Mix (Promega, Madison, WI, USA). To amplify the glycoprotein D (gD) gene, the following primers were used: ForwgDm (5'GTGCACGGAGGACGAGCTGGGGCT-3') and RevgDm (5'-GACGTCCACGCCCCGCTTGAAGCT3 '). Denaturation, annealing and extension consisted of 35 cycles at $95^{\circ} \mathrm{C}$ for $45 \mathrm{~s}, 60^{\circ} \mathrm{C}$ for $45 \mathrm{~s}$ and $72^{\circ} \mathrm{C}$ for $45 \mathrm{~s}$, respectively. The PCR products were visualized on $1 \%$ agarose stained with ethidium bromide.

Partial gC was amplified using the primers $\mathrm{gC}-2 \mathrm{U}$ GTTTCCTGATTCACGCCCACGC and $\mathrm{gC}-1 \mathrm{~L}$ GAAGGGCTCACCGAAGAGGAC (Goldberg et al., 2001), which gave an expected product of 788 nucleotides. The reaction mixtures were cycled as follows: a denaturation step of $95^{\circ} \mathrm{C}$ for $5 \mathrm{~min}, 8$ cycles of $95^{\circ} \mathrm{C}$ for $50 \mathrm{~s}, 67^{\circ} \mathrm{C}$ for $50 \mathrm{~s}, 72^{\circ} \mathrm{C}$ for $50 \mathrm{~s}, 27$ cycles of $95^{\circ} \mathrm{C}$ for $50 \mathrm{~s}, 64^{\circ} \mathrm{C}$ for $50 \mathrm{~s}, 72^{\circ} \mathrm{C}$ for $50 \mathrm{~s}$ and an extension step of $72^{\circ} \mathrm{C}$ for 5 min (Fonseca et al., 2010). The PCR products were visualized on $1 \%$ agarose gels and purified according to the manufacturer's protocols using Wizard SV Gel and PCR Clean-Up System (Promega, Madison, WI, USA), and sequenced on both strands of each product by using the Big Dye Terminator V 3.1 sequencing kit (Applied Biosystems, Germany) with the same primers used for amplification. The sequences were analyzed on an ABI3130XL genetic analyzer (Applied Biosystems, USA), at the Unidad de Genómica, INTA Castelar, Argentina.

Sequence analysis and alignment of nucleotide sequences

The sequence was edited using BioEdit Sequence Alignment Editor. Homology analyses were performed with the BLASTN program (National Center for Biotechnology

[http://www.ncbi.nlm.nih.gov/BLAST/]).
The sequence alignments of the partial gC gene were performed with the ClustalW method, using the MEGA 7.0 program. The phylogenetic analysis was carried out with the same program, using the neighbor-joining (NJ) method with the Kimura two-parameter model, and bootstrap analyses were conducted using 1000 replicates.

The dataset included 68 strains from different countries available through GenBank, including the Argentinean SuHV-1 swine strains (Table 1).

\section{Virus neutralization test}

Sera from pigs living in a farm near the place where the dog lived were analyzed by the virus neutralization test. The serum samples were heat-inactivated at $56^{\circ} \mathrm{C}$ for $30 \mathrm{~min}$ and serial two-fold dilutions were prepared in serum-free medium in 96-well flat-bottom tissue culture plates (Nunc, Rochester, NY, USA).

Virus suspension with a titer of 100 TCID $_{50}$ in $25 \mu \mathrm{l}$ was added to each serum dilution well and the mixture was incubated for $1 \mathrm{~h}$ at $37^{\circ}$ and $5 \% \mathrm{CO}_{2}$ and then 100 $\mu \mathrm{l}$ of an RK13 cell line suspension $\left(3 \times 10^{5}\right.$ cells $\left./ \mathrm{ml}\right)$ was added to each well and incubated for $72 \mathrm{~h}$. Appropriate serum, virus and cell controls were included in this test. The plates were observed under a microscope for CPE.

\section{Histopathological analysis}

Samples of the lateral area of a cerebral hemisphere (including cranial, media and caudal zones) were embedded in paraffin wax for histological examination, sectioned at 3-4 $\mu \mathrm{m}$ and stained with hematoxylin and eosin. Neither cerebellum nor brain stem was available.

\section{Results}

\section{History and origin of the dog samples}

The brain tissue and trigeminal ganglia analyzed were from a dog that lived close (about $1500 \mathrm{mts}$ ) to the SuHV-1-positive pig farm located in Chañar Ladeado, Santa Fe Province.

The map with georeferencing of the sample is shown in Figure 1.

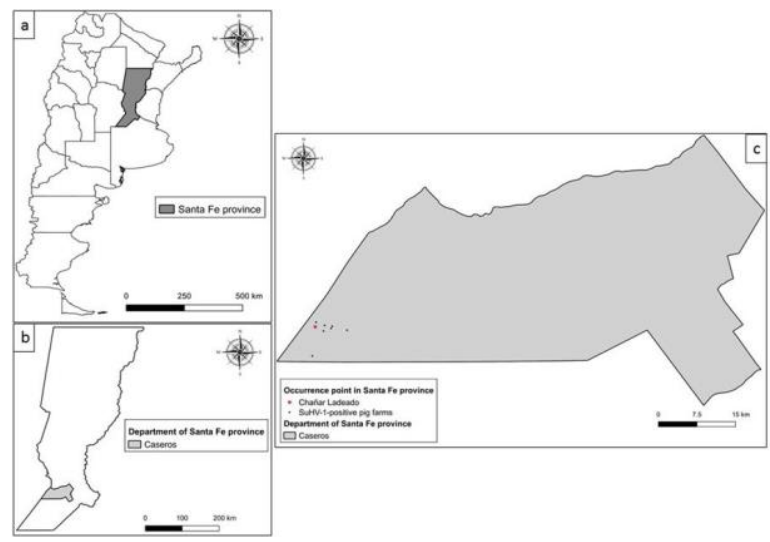

Fig. 1. Map of Argentina (a) showing the location of Santa Fe Province (b) and Chañar Ladeado City (c) (QGis (version 2.18.3). 
Table 1. Origin, species and accession numbers of the SuHV-1 strains used in this study.

\begin{tabular}{|c|c|c|c|c|c|}
\hline $\begin{array}{c}\text { GenBank } \\
\text { Accession } \mathrm{N}^{\circ}\end{array}$ & Origin & Species & $\begin{array}{c}\text { GenBank } \\
\text { Accession } \mathrm{N}^{\circ}\end{array}$ & Origin & Species \\
\hline AF176495 & USA & Swine & JF460034.1 & Argentina & Swine \\
\hline AF176484.1 & USA & Dog & JF460035 & Argentina & Swine \\
\hline AF176488 & USA & Swine & JF767011.1 & USA & Dog \\
\hline AF176489 & USA & Swine & JQ768109 & Italy & Dog \\
\hline AF176489.1 & USA & Swine & JQ768122 & Italy & Dog \\
\hline AF176491 & USA & Swine & JQ768125 & Italy & Dog \\
\hline AF403051 & China & Cow & JQ768151 & Italy & Swine \\
\hline AF158090 & China & Swine & JQ768152 & Italy & Swine \\
\hline D49435.1 & Japan & Swine & JQ768154 & Italy & Dog \\
\hline D49436.1 & USA & Swine & JQ768156 & Italy & Dog \\
\hline D49437.1 & Ireland & Swine & JQ081285.1 & Austria & Hunting dog \\
\hline EU622054.1 & Brazil & Swine & JQ081286.1 & Austria & Hunting dog \\
\hline EU622055 & Brazil & Swine & JQ081289.1 & Austria & Hunting dog \\
\hline EU622056 & Brazil & Swine & JQ081291.1 & Austria & Hunting dog \\
\hline EU622057.1 & Brazil & Swine & JQ081292.1 & Austria & Hunting dog \\
\hline EU622058.1 & Brazil & Swine & JQ081293.1 & Austria & Hunting dog \\
\hline EU622059.1 & Brazil & Swine & KC865672 & Croatia & Swine \\
\hline EU622069.1 & Brazil & Swine & КС865680.1 & Croatia & Dog \\
\hline EU622071.1 & Brazil & Swine & KF779458 & Belgium & Hunting dog \\
\hline EU622079 & Brazil & Cow & KF779463 & Belgium & Swine \\
\hline GQ862778.1 & Germany & Hunting dog & KF779468 & Belgium & Swine \\
\hline GQ259098 & France & Hunting dog & KP780805.1 & Italy & Dog \\
\hline GQ259099.1 & France & Hunting dog & KP780806.1 & Italy & Dog \\
\hline GQ259100 & France & Hunting dog & KP862611.1 & Italy & Hunting dog \\
\hline GQ259105 & Germany & Hunting dog & KP862612.1 & Italy & Hunting dog \\
\hline GQ259106 & Germany & Hunting dog & KP862613.1 & Italy & Hunting dog \\
\hline GQ259115 & France & Hunting dog & KP862614.1 & Italy & Hunting dog \\
\hline GQ259116 & Germany & Hunting dog & KP862615.1 & Italy & Hunting dog \\
\hline JF460027 & Argentina & Swine & KP862616.1 & Italy & Dog \\
\hline JF460029 & Argentina & Swine & KP862617.1 & Italy & Dog \\
\hline JF460030.1 & Argentina & Swine & KP862618.1 & Italy & Dog \\
\hline JF460031.1 & Argentina & Swine & KP862619.1 & Italy & Hunting dog \\
\hline JF460032.1 & Argentina & Swine & KP862620.1 & Italy & Hunting dog \\
\hline JF460033.1 & Argentina & Swine & KP862621.1 & Italy & Hunting dog \\
\hline
\end{tabular}

Epidemiological investigations were conducted by a veterinary doctor, who declared that the animal had direct contact with the pigs or had been fed with SuHV1 -infected meat. Clinical signs in the dog included neurological signs, such tremors, trismus, spasms of muscles of the larynx and pharynx, dyspnea, vomiting and pruritus. Death occurred within 24-48 h.

\section{Virus isolation and identification}

SuHV-1 was isolated from the brain and trigeminal ganglia in tissue culture in a confluent monolayer of
RK13 cells. CPE was observed on day 4 of the first passage. Typical herpesvirus CPE, including lysis and syncytium formation, was observed in the two samples analyzed. Two more passages were done to increase the virus titer, but the magnitude of the $\mathrm{CPE}$ remained constant (Fig. 2).

SuHV-1 genotyping of the virus isolated from the brain of the dog analyzed was performed by RFLP. The strain analyzed exhibited the classical restriction pattern present in SuHV-1 genotype I (Herrmann et al., 1984). 
In addition, it showed no alterations involving the gain or loss of BamHI cleavage sites, as also seen in all Argentinean strains reported previously, which present almost the same pattern, with small differences and a main variation in the 5+14', 10 and 12 fragments (Serena et al., 2010) (Fig. 3).

The DNA extracted from the infected cells was found to be SuHV-1-positive by PCR detecting gD (217 bp). The $\mathrm{gC}$ gene was then specifically amplified and the product was the expected size.

The PCR assay generated a product yielding a sharp, visible band around $750 \mathrm{bp}$ on an ethidium bromide gel. An identical band was obtained from the positive control and no band was observed in the negative control used in the assay. The partial sequence of the $\mathrm{gC}$ gene of the dog strain analyzed was confirmed by BLAST analysis, which revealed $100 \%$ of similarity with the SuHV-1 strain NIA-3 (complete genome KU900059.1).

No rabies virus was detected in the brain sample by using the RT-PCR technique. All the serum samples from the pigs from the neighboring farm analyzed by the virus neutralization test were SuHV-1-positive, with titers between 1:8 and 1:32.

\section{Histopathological analysis}

In all examinated areas of brain, the histopathological study revealed sparse mononuclear cell infiltration in meninges, and mild diffuse gliosis and neuronal satellitosis in gray matter.

Most neurons appeared unaffected, although a few evidenced shrinkage with condensed hypereosinophilic cytoplasm and pyknotic nuclei. These findings were compatible with mild non-specific encephalitis (Fig. 4).

\section{Phylogenetic analysis based on $\mathrm{gC}$}

The partial nucleotide sequence data for the partial $\mathrm{gC}$ gene reported here have been previously submitted to GenBank under accession number MF101748.
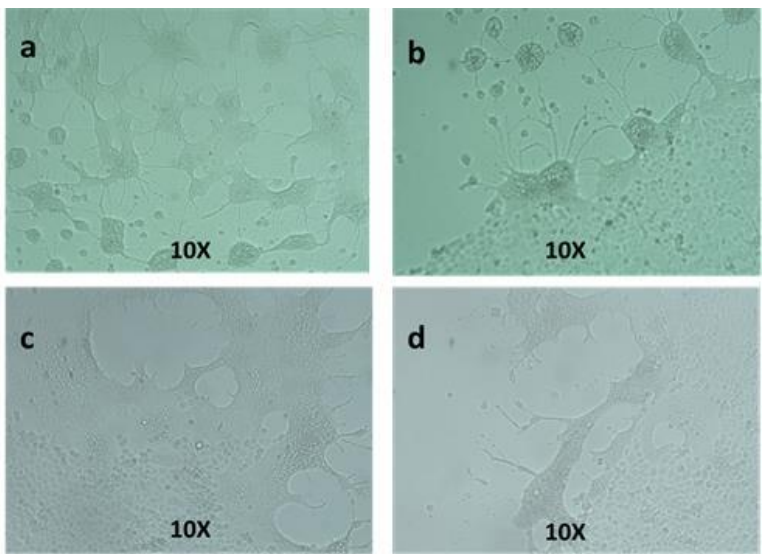

Fig. 2. Typical herpesvirus cytopathic effect characterized by lysis and syncytium formation, detected in RK13 cells. Brain (a and b), trigeminal ganglia (c and d) after $72 \mathrm{~h}$ pi.

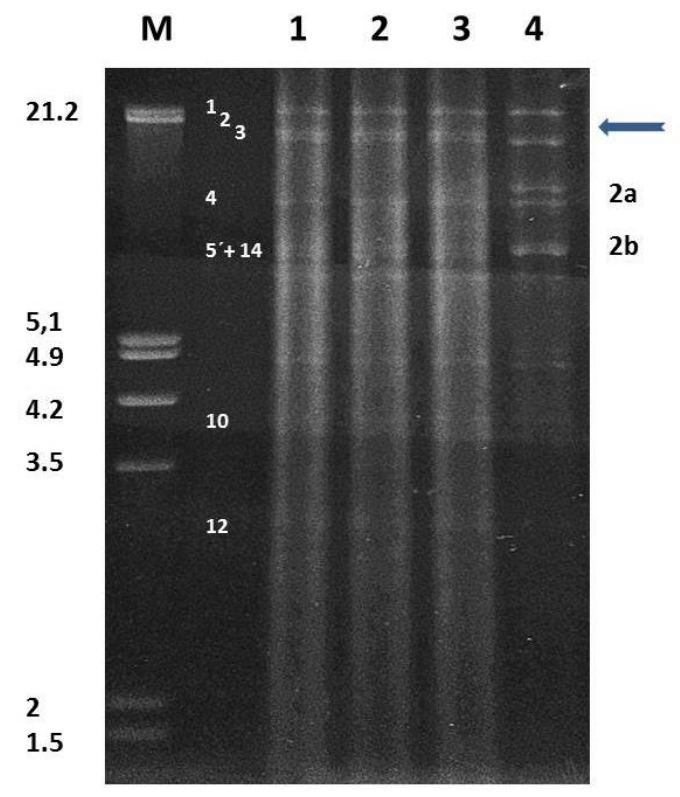

Fig. 3. Restriction fragments obtained with the BamHI enzyme. M: Lambda DNA cleaved with EcoRI + HindIII (size expressed in Kbp). Lane 1: DNA ARG-Dog 2015 isolated from brain. Lane 2: DNA ARG-Dog 2015 isolated from trigeminal ganglion. Lane 3: Indiana-S Type I reference strain. Lane 4: Yamagata S-81 Type II reference strain. Representative Type fragments are numbered according to Hermann et al. (1984) for type I (left numbers) and type II (right numbers). The arrow indicates absence of fragment 2 in type II.
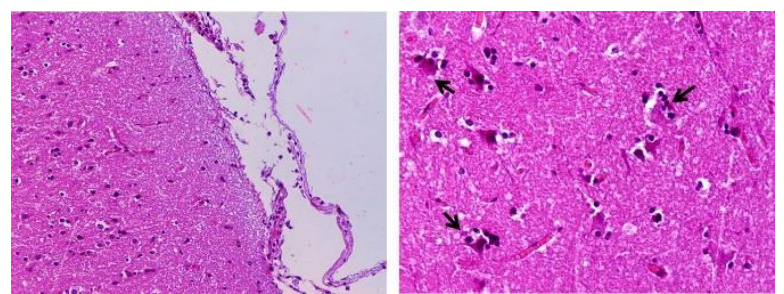

Fig. 4. The histopathological study revealed sparse mononuclear cell infiltration in meninges, H\&E (left 20X) and few neurons evidence acute eosinphilic degeneration with shrunken eosinophilic soma and pyknotic nuclei in brain (gray matter). Phagocytes around the cell body (satellitosis) are seen, $\mathrm{H} \& \mathrm{E}$ (right $40 \mathrm{X}$ ).

Phylogenetic analysis of the gene encoding the $\mathrm{gC}$ protein demonstrated that the dog strain analyzed, named ARG-Dog 2015, showed no differences with swine Argentinean SuHV-1 strains and all together grouped in Cluster A, together with the NIA-3 reference strain. This cluster showed three groups: group a1, represented by swine Argentinean strains including the new Dog strain, swine Brazilian strains, one canine US strain and two reference strains (NIA-3 and Indiana-S); group a2, represented by one canine US strain and various swine US strains; and group a3, represented by four canine Italian strains. 
Cluster B was formed by two defined groups, b1 and b2: b1 is represented by three hunting dog Austrian strains, whereas group b2 is represented by two swine Belgian strains, one swine Croatian strain, one canine Croatian strain, two hunting dog strains from Germany and France, two swine Italian strains, five canine Italian strains and two swine Brazilian strains, all of them with a high degree of homology to the reference strain Yamagata S-81. Cluster C was represented by three different groups: group c1, which included hunting dog strains from Germany, France and Belgium; group c2, which included three strains from Austria; and group c3, which included nine Italian strains. Groups c2 and c3 were closely related to the Shope reference strain. The Asian strains Fa and Ea were clustered separately and formed a new cluster named Cluster D, which was genetically divergent from all strains analyzed (Fig. 5). An alignment of the deduced amino acid sequences of the $\mathrm{gC}$ protein showed several insertions and/or deletions as described previously in positions 24,25 , 38, 39, 181 and 182. Among the strains of group a1, the new Dog strain, the swine Argentinean strains, NIA-3 and one canine US strain (JF767011.1) showed a gap in positions 181 and 182. The rest of the strains of group a1, except the Indiana-S reference strain, also presented another gap in position 39. The Indiana-S strain showed the same variation inside the group because it presented one gap in position 181 and another gap in positions 24 and 25 , but did not present the gap in position 39 . The strains belonging to group a2 represented by US isolates showed only one gap in position 181. All strains of group a3 formed by canine Italian isolates presented all the gaps described. In Cluster B, none of the strains that formed group b1 and three strains of group b2 (GQ862778.1, KC865680.1 and KC865672) presented no gaps. The rest of the strains of group b2, except the Yamagata S-81 reference strain, presented two gaps: one in positions 24 and 25, and another in position 39. The Yamagata S-81 strain was the only strain of group b2 that had only one gap in positions 24 and 25. Analysis of Cluster $\mathrm{C}$ showed that all the strains of group $\mathrm{c} 1$ showed gaps in positions 181 and 182. One strain of this group (GQ259115) also presented one gap in positions 24 and 25, while the rest of the strains belonging to the group and all the strains from group $\mathrm{c} 2$ presented two gaps: one in the same position and another in positions 38 and 39. The strains of group c3 contained two deletions at positions 24 and 181. Cluster D was represented by Asian strains characterized by a long insertion (eight amino acids) from position 62 to position 69, present only in these strains. The Ea and $\mathrm{Fa}$ reference strains also had an insertion of two amino acids in positions 181 and 182. The phylogenetic tree from the amino acid sequence analysis maintained the same distribution of groups, differing only in the branch positions (data not shown).

\section{Discussion}

SuHV-1 was identified in a dog with history of exposure to a serologically positive swine farm, clinical signs and histopathological lesions. The virus was isolated and the infection was confirmed by RFLP, PCR and sequence analysis. Besides, the presence of virus antibodies in the neighboring swine farm was analyzed by the virus neutralization test from serum samples and positive results were detected. In the countries where SuHV-1 has been eradicated, researchers investigated the presence of the virus in wild boars and in dogs related to the swine farm or feral swine as well as in hunting dogs (Cramer et al., 2011; Steinrigl et al., 2012; Moreno et al., 2015).

Argentina has a valid eradication program of pseudorabies based on a serological test in the swine farm population and feral swine where we, as a reference laboratory, collaborate with SENASA. This program has shown a high prevalence of SuHV-1 in Santa Fe Province, where we detected the canine clinical case.

Pseudorabies is one of the most economically important diseases of farmed pigs. Both farmed pigs and wild boars can act as reservoirs and might represent a potential threat for occasional animals as dogs. Several reports have described the situation of SuHV-1 in dogs and their association and contact with live and/or dead feral pigs. It is not known whether the dogs become infected by consuming carcasses of dead feral pigs or whether they are exposed to the virus during hunting or fighting with live pigs (Cramer et al., 2011).

The dog analyzed presented a variety of clinical signs compatible with SuHV-1 infection, including the most classical clinical sign: facial pruritus (Pejsak and Truszczynski, 2006). Differential diagnosis for dogs exhibiting these clinical signs includes rabies infection which was discarded by the negative RT-PCR result. The RFLP pattern of the ARG-Dog 2015 isolate suggests that it belongs to genotype I, as all the swine Argentinean strains previously isolated. The swine Argentinean viruses have been classified as type I, suggesting that no major variation has occurred in SuHV-1 spreading in Argentina since the first outbreak was noticed. The new isolate from the dog analyzed here supports this appreciation. The Argentinean type I strains had a high degree of BamHI pattern identity to the Indiana-S reference strain, especially in fragment 5+14' (Serena et al., 2010). It is well known that the most noticeable change in the vaccine strain profile is the absence of BamHI fragment \#7 (Petrovskis et al., 1986). No deletion of BamHI fragment \#7 was observed in the ARG-Dog 2015 isolate or the Argentinean strains, indicating that they are wild-type viruses. The RFLP analysis, together with the phylogenetic analysis, allowed differentiating groups of strains relating genotype and origin of isolates. 


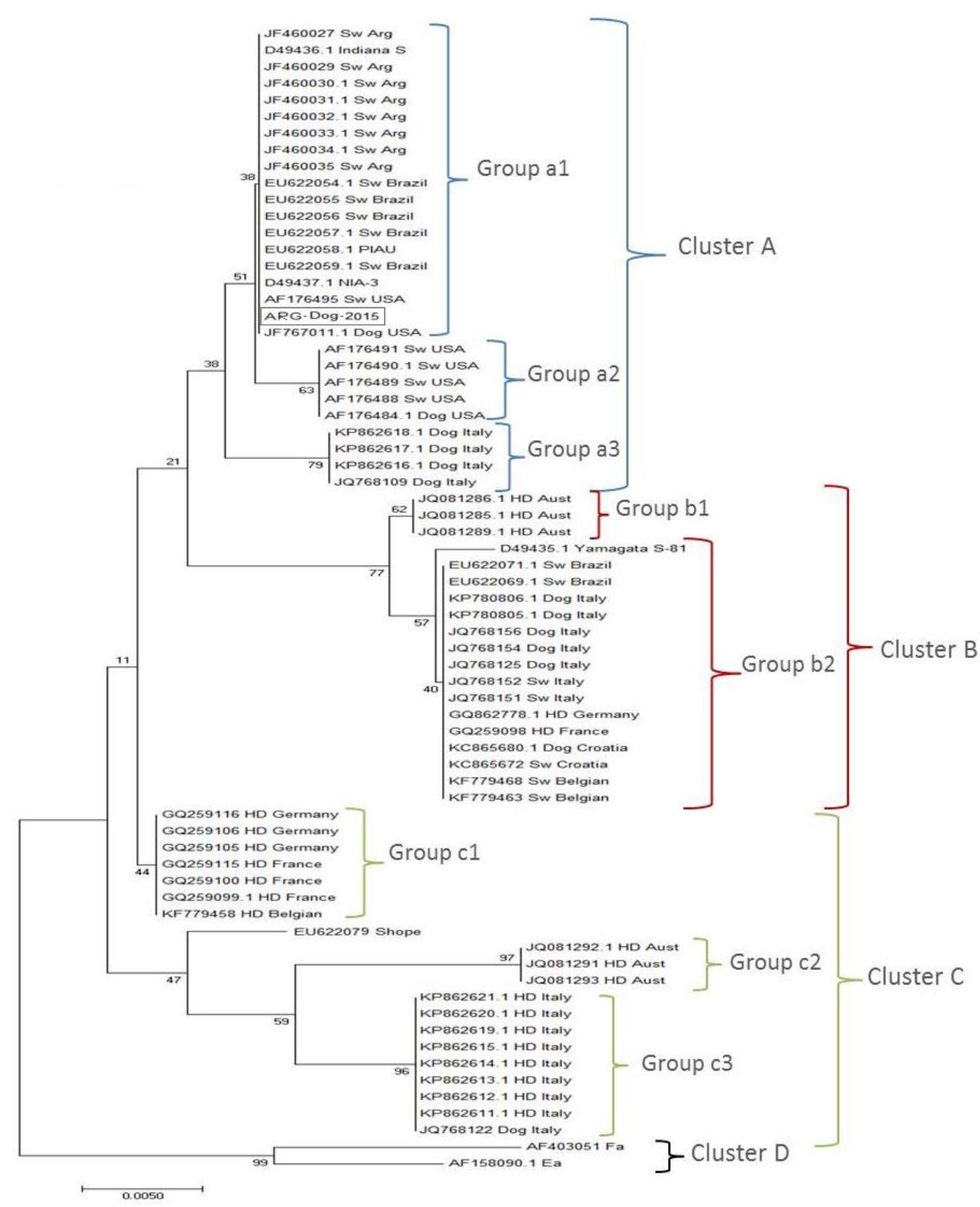

Fig. 5. Phylogenetic tree obtained by the neighbor-joining (NJ) method with the Kimura two-parameter model and bootstrap analyses using 1000 replicates from the analysis of the partial $\mathrm{gC}$ gene amplified by polymerase chain reaction of Argentinean and international SuHV-1 strains.

In contrast to RFLP analysis, phylogenetic analysis is faster, avoids the need for virus isolation, and has the advantage that reference sequences are easily available. Goldberg et al. (2001) reported significant correlation between RFLP and $\mathrm{gC}$ sequence distance.

The histological pattern typical of canine SuHV-1 is characterized by nonsuppurative inflammation showing mononuclear cell perivascular cuffing, gliosis, neuronal degeneration, neuronophagia and intranuclear inclusion bodies in neurons and astrocytes (Cramer et al., 2011).

While the histopathological study revealed a lesion compatible with non-specific encephalitis, it must be pointed out that the sample of brain analyzed was partial. As described by Cramer et al. (2011), the most common lesion in dogs is observed in the brainstem, including the cranial nerves, but these samples were not available in this study. The phylogenetic tree based on the analysis of the $\mathrm{gC}$ gene revealed four different clusters. There was a clear distinction between the viral strains isolated from the Americas and those isolated from Europe, as well as between the strains isolated from hunting dogs and the strains isolated from working farm dogs and/or domestic pigs. Similar results were obtained by Moreno et al. (2015), who detected that the Italian strains were distributed into 
three different clusters and that there was a clear distinction between the wild boar strains (and those isolated from dogs that were used for hunting and subsequently traced back to wild boars) and the strains isolated from working farm dogs (and found to be closely related to strains in domestic pigs). The new Dog strain was located in a separate group (a1) inside Cluster A, together with swine Argentinean and Brazilian strains belonging to genotype I, with a US strain isolated from a dog (JF767011.1) and with the reference strains NIA-3 and Indiana-S. A similar distribution was observed by Cramer et al. (2011), who found that the dog strain isolate was grouped separately from other US strains and demonstrated notable divergence from the Indiana-S strain. In our study, including Argentinean strains, they formed a separate group, even with Indiana-S. Group a3 was represented by dog strains from Italy previously described as related to those found in domestic pigs clustered in clade 2 by Moreno et al. (2015).

SuHV-1 isolates representative of genomic type I are found in the USA and Central Europe, while isolates showing genomic type II are found predominantly in Central Europe and Japan (Sozzi et al., 2014). Genomic characterization based on sequencing of the $\mathrm{gC}$ gene showed a good correlation between genotype I and Cluster A as well as between genotype II and Cluster B. Inside Cluster B, there was a clear distinction between swine strains and canine strains originating from working dogs in pig farms (group b2), as described by Sozzi et al. (2014) and classified mainly as genotype II by Müller et al. (2010), and those originating from hunting dogs from Austria (group b1), represented as lineage 2 in a previous study and described as genotype I (Steinrigl et al., 2012).

Cluster $\mathrm{C}$ separated strains from hunting dogs related to wild boar strains from Europe. We obtained a distribution of the groups similar to that obtained by other authors, where cluster C in Sozzi's report and clade 1 in Moreno's report were represented in group c3 in our study. The differentiation of the groups in the tree based on the amino acid sequences revealed insertions and deletions and the results were similar to those of other studies (Müller et al., 2010; Steinrigl et al., 2012; Sozzi et al., 2014; Moreno et al., 2015).

SuHV-1 has virtually disappeared from domestic pigs in many parts of the world, but is still a problem in some South American countries. The genomic characterization of SuHV-1 strains originating from swine and other mammals might help to better understand the population diversity and facilitate tracing the infection chain back to its origin (Sozzi et al., 2014). The results of this study provide an update of the knowledge of pseudorabies in dogs and the role of these animals in the viral infection in relation with their contact with pigs.

\section{Acknowledgements}

We thank to Mr. Claudio Leguizamón, Ms. Adriana Conde and Ms. Mariela Vazzano for their technical assistance.

\section{Conflict of interest}

The authors declare that there is no conflict of interests.

\section{References}

Ambrogi, A., Giraudo, J., Busso, J., Bianco, B., Bagnat, E., Segura de Aramburu, M., Ramos, B. and Ceriatti, S. 1981. Primer diagnóstico de la Enfermedad de Aujeszky en cerdos en la República Argentina. Gac.Vet. 43, 58-64.

Ben-Porat, T., Deatly, A., Easterday, B., Galloway, D., Kaplan, A. and McGregor, S. 1984. Latency of pseudorabies virus. In: Wittmann, G., Gaskell, R.M., Rziha, H.J. (Eds.), Latent Herpes Virus Infections in Veterinary Medicine, Current Topics in Veterinary Medicine and Animal Sciences, vol. 27. Martinus Nijhoff Publishers, Boston, USA, pp: 365-383.

Cay, A. and Letellier, C. 2009. Isolation of Aujeszky's disease virus from two hunting dogs in Belgium after hunting wild boars. Vlaams Diergeneeskundig Tijdschrift 78, 194-195.

Christensen, L. 1995. The population biology of Suid Herpes virus 1. APMIS Suppl. 48, 1-48.

Cisterna, D., Bonaventura, R., Cailloub, S., Pozoc, O., Andreaud, M., Dalla Fontana, L., Echegoyen, C., de Mattos, C., Russo S., Novaroh, L., Elbergerh, D. and Freire, M.C. 2005. Antigenic and molecular characterization of rabies virus in Argentina. Virus Res. 109, 139-147.

Cramer, S., Campbell G., Morgan, S., Smith, S., McLin, W., Brodersen, B., Wise, A., Scherba, G., Langohr, I. and Maes, R. 2011. Pseudorabies virus infection in Oklahoma hunting dogs. J. Vet. Diag. Invest. 23, 915-923.

Davido, M. 1981. Enfermedad de Aujeszky en el sur de la Provincia de Córdoba. Gac. Vet. 44, 291-296.

Echeverría, M., Nosetto, E., Petruccelli, M., Gimeno, E. and Etcheverrigaray, M. 1991. Ocurrencia y diagnóstico de la Enfermedad de Aujeszky en las zonas de Chañar Ladeado y Saladillo. Vet. Argentina 8, 252-257.

Echeverría, M., Nosetto, E., Etcheverrigaray, M., Galosi, C., Fonrouge, R., Pereyra, N., Belak, K. and Gimeno, E. 1992. Pseudorabies (Aujeszky's disease) in Argentina. Rev. Sci. Tech. Off. Int. Epiz. 11, 819-827.

Echeverría, M., Norimine, J., Galosi, C., Oliva, G., Etcheverrigaray, M. and Nosetto, E. 1994. The genotype of Aujeszky's Disease viruses isolated in Argentina. J. Vet. Med. Sci. 56, 985-987.

Echeverría, M., Pecoraro, M., Pereyra, N., Pidone, C., Galosi, C., Etcheverriagaray, M. and Nosetto, E. 
2000. Rapid diagnosis of pseudorabies virus in swine tissues using a polymerase chain reaction method. Rev. Argent. Microbiol. 32, 109-115.

Fonseca, A., Fernandez Camargos, M., Macedo de Oliveira, A., Ciacci-Zanella, J., Patricio, M., Braga, A., Cunha, E., D’Ambros, R., Heinemann, M., Cerqueira Leite, R. and Pimenta dos Reis, J. 2010. Molecular epidemiology of Brazilian pseudorabies viral isolates. Vet. Microbiol. 141, 238-245.

Gielkens, A., Van Oirschot, J. and Berns, A. 1985. Genome differences among field isolates and vaccine strains of pseudorabies virus. J. Gen. Virol. $66,69-82$.

Goldberg, T., Weigel, R., Hahn, E. and Scherba, G. 2001. Comparative utility of restriction fragment length polymorphism analysis and gene sequencing to molecular epidemiological investigation of a viral outbreak. Epidemiol. Infect. 126, 415-424.

Herrmann, S., Heppner, B. and Ludwig, H. 1984. Pseudorabies virus from clinical outbreaks and latent infections grouped into four major genome types. In: Wittmann G, Gaskell R, Rziha H, editors. Latent herpesvirus infections in veterinary medicine, current topics in veterinary medicine and animal science. Boston, USA. Martinus Nujhoff Pub, pp: 387-401.

Moras, E., Ierace, A., Barboni de Stella, A., Iribarren, F., Barcos, O. and Menchaca, E. 1986. Segundo aislamiento de Herpes suis en un brote de enfermedad de Aujeszky en caninos de la provincia de La Pampa. II Congreso Argentino de Virología, 20-24 de octubre 1986, Córdoba, Argentina.

Moreno, A., Sozzi, E., Grilli, G., Gibelli, L, ,Gelmetti, D., Lelli, D., Chiari, M., Prati, P., Alborali, G., Boniotti, M, Lavazza, A. and Cordioli, P. 2015. Detection and molecular analysis of Pseudorabies virus strains isolated from dogs and a wild boar in Italy. Vet. Microbiol. 177, 359-365.

Müller, T., Klupp, B., Freuling, C., Hoffmann, B., Mojcicz, M., Capua, I., Palfi, V., Toma, B., Lutz, W., Ruiz-Fon, F., Gortarzar, C., Hlinak, A., Schaarschmidt, U., Zimmer, K., Conraths, F., Hahn, E. and Mettenleiter, T. 2010. Characterization of pseudorabies virus of wild boar origin from Europe. Epidemiol. Infect. 138, 1590-1600.

Müller, T., Hahn, E., Tottewitz, F., Kramer, M., Klupp, B., Mettenleiter, T. and Freuling, C. 2011. Pseudorabies virus in wild swine: a global perspective. Arch. Virol. 156, 1691-1705.

Pejsak, Z. and Truszczynski, M. 2006. Aujeszky's disease (pseudorabies). In: Diseases of swine, ed. Straw, B.E., Zimmerman, J.J., D’Allaire, S., Taylor, D.J., $9^{\text {th }}$ ed., Blackwell, Ames, IA, pp: 419-433.

Petrovskis, E., Timmins, J., Gierman, T. and Post, L.
1986. Deletions in vaccine strains of pseudorabies virus and their effect on synthesis of glycoprotein gp63. J. Virol. 60, 1166-1169.

Piatti, R., Ikuno, A., Cunha, E., D’Ambros, R., Gregori, F., Soares, R., Cortez, A. and Richtzenhain, L. 2001. Characterization of Aujeszky's disease virus isolates from South and Southeast Brazil by RFLP analysis. Braz. J. Microbiol. 32, 144-146.

Pirtle, E., Wathen, M., Mengeling, W. and Sacks, J. 1984. Evaluation of field isolates of pseudorabies virus (Aujeszky's disease) as determined by restriction endonuclease analysis and hybridisation. Am. J. Vet. Res. 45, 1906-1912.

Sager, R., Rossanigo, C., Vázquez, R., Avila, J. and Fondevila, N. 1984. Enfermedad de Aujeszky en cerdos en Villa Mercedes (San Luis) Argentina. Revista de Medicina Veterinaria 65, 86-89.

Schaefer, R., Ciacci-Zanella, J., Mores, N., Kleitton, A., Dambros, R., Schiochet, M. and Coldebella, M. 2006. Characterization of Aujeszky's disease virus isolated from South Brazil in the last twenty years by restriction enzyme analysis. Braz. J. Microbiol. 37, 390-394.

Serena, M., Metz, G., Martín Ocampos, G., Gambaro, S., Mórtola, E. and Echeverría, M. 2010. Characterization of Suid herpesvirus 1 field isolates from Argentina. Rev. Argent. Microbiol. 42, 179183.

Serena, M., Metz G, Mórtola, E. and Echeverría, M. 2011. Phylogenetic analysis of Suid Herpesvirus 1 isolates from Argentina. Vet. Microbiol. 154, 7885.

Sozzi, E., Moreno, A., Lelli, D., Cinotti, S.,Alborali, G.L., Nigrelli, A., Luppi, A., Bresaola, M., Catella, A. and Cordioli, P. 2014. Genomic Characterization of Pseudorabies Virus Strains Isolated in Italy. Transbound. Emerg. Dis. 61, 334-340.

Steinrigl, A., Revilla-Fernández, S., Kolodziejek, J., Wodak, E., Bagó, Z., Nowotny, N., Schmoll, F. and Köfer, J. 2012. Detection and molecular characterization of Suid herpesvirus type 1 in Austrian wild boar and hunting dogs. Vet. Microbiol. 157, 276-284.

Tisdall, D., Bentley, C. and Horner, G. 1988. Genetic variation between New Zealand and Western Samoan isolates of Aujeszky's disease virus. Vet. Microbiol. 17, 335-343.

Todd, D. and Mc Ferran, J. 1985. Restriction endonuclease analysis of Aujeszky's disease (pseudorabies) virus DNA comparison of Northern Ireland isolates and isolates from other countries. Arch. Virol. 86, 167-176.

Wittmann, G. 1986. La enfermedad de Aujeszky. Rev. Sci. Tech. Off. Int. Epiz. 5, 995-1009. 